\title{
Design and implementation of Arduino based robotic arm
}

\author{
Hussein Mohammed Ali, Yasir Hashim, Ghadah Alaadden Al-Sakkal \\ Department of Computer Engineering, Tishk International University, Kurdstan Region, Erbil, Iraq
}

\begin{tabular}{l} 
Article Info \\
\hline Article history: \\
Received May 17, 202 \\
Revised Jul 14, 2021 \\
Accepted Aug 12, 202 \\
\hline Keywords: \\
Arduino \\
Autonomous system \\
Distance control \\
Microcontroller \\
Mobile application \\
Robotic arm
\end{tabular}

Robotic arm

\begin{abstract}
This study presents the model, design, and construction of the Arduino based robotic arm, which functions across a distance as it is controlled through a mobile application. A six degree of freedom robotic arm has been designed and implemented for the purpose of this research. The design controlled by the Arduino platform receives orders from the user's mobile application through wireless controlling signals, that is Bluetooth. The arm is made up of five rotary joints and an end effector, where rotary motion is provided by the servomotor. Each link has been first designed using solid works and then printed by 3D printer. The assembly of the parts of the robot and the motor's mechanical shapes produce the final prototype of the arm. The Arduino has been programmed to provide rotation to each corresponding servo motor to the sliders in the designed mobile application for usage from distance.
\end{abstract}

This is an open access article under the CC BY-SA license.

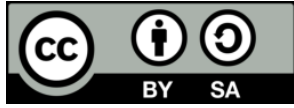

\section{Corresponding Author:}

Yasir Hashim

Department Computer Engineering, Faculty of Engineering, Tishk International University

Erbil-Kurdistan, Iraq

Email: yasir.hashim@tiu.edu.iq

\section{INTRODUCTION}

Autonomous systems and robots can contribute in plenty of functional operations over the world. The robotic arm can solve many limitations of humans in industrial fields especially with the aid of the distance controlled feature. Robotic arms' functions and their operations are extensively used in research laboratories and industries to automate processes and reduce human errors. Some of the tasks achieved by robotic arms include assembly lines and motions that demand the force control with feedback to its controller [1], [2].

Robotic systems have grown broadly due to their increasing applications in all fields of industry and their ability to decrease errors and wastage of material. Many different robotic systems have been developed for invasive proposes [3], [4]. The robotic arms could initially be used to move objects from one place to another [5], [6] in any industrial area [7], [8] that needs to achieve tasks repetitively for manufacturing products. Some industrial environments are not suitable for humans, thus robotic arms may be used. For instance, cases in which human workers cannot easily or safely gain access are handling radio-active materials or dealing with work in the deep sea and space [9], [10]. Generally, the two main purposes of the robotic arm systems are to minimize the risk of life by ensuring human safety, and to speed up industrial processes. This is where an automated, simple, and effective Arduino controlled robotic arm comes into play [11], [12]. The arm could be used for numerous tasks such as painting cars, soldering cars access unevenly placed parts for scanning, selecting. Most of the food industry companies use pick and place robots, which is useful in many criteria. In a human-designed environment, the robotic arm can also operate on a mobile base to be sent in a damaged/radioactive building and used to open the doors and manipulate the tools either by itself or through remote control [13], [14]. Table 1 illustrates a technical review on features of some robotic arms designed by researchers. 
Table 1. Technical review on designed robotic arms

\begin{tabular}{|c|c|c|c|c|c|}
\hline Studies & Issue (Problem) & Method & Advantage & Disadvantage & Ref. \\
\hline $\begin{array}{l}\text { Low cost platform } \\
\text { for automatic } \\
\text { control education }\end{array}$ & $\begin{array}{l}\text { Education based } \\
\text { development only }\end{array}$ & $\begin{array}{l}\text { It is an on open } \\
\text { hardware }\end{array}$ & $\begin{array}{l}\text { Low-cost platform } \\
\text { for automation }\end{array}$ & $\begin{array}{c}\text { Open hardware is a risk } \\
\text { because of incompatibility }\end{array}$ & [14] \\
\hline $\begin{array}{l}\text { Development of a } \\
\text { multi-purpose, } \\
\text { modular, low cost } \\
\text { robotic arm for } \\
\text { education and } \\
\text { unmanned } \\
\text { platforms }\end{array}$ & $\begin{array}{l}\text { For education } \\
\text { proposes and a low } \\
\text { cost robotic arm }\end{array}$ & $\begin{array}{l}\text { Modular robotic } \\
\text { arm }\end{array}$ & $\begin{array}{l}\text { 3D printable and } \\
\text { low cost, multi- } \\
\text { purpose }\end{array}$ & $\begin{array}{l}\text { Specific operations with } \\
\text { programmed motors need } \\
\text { skilled engineers }\end{array}$ & [15] \\
\hline $\begin{array}{l}\text { Self-calibration of a } \\
\text { biologically } \\
\text { inspired } 7 \text { DOF } \\
\text { robotic arm with } \\
\text { cable driven. }\end{array}$ & $\begin{array}{l}\text { The design of a } 7 \\
\text { DOF robotic arm } \\
\text { with cable-driven } \\
\text { movements is } \\
\text { limited to only one } \\
\text { direction at a time. }\end{array}$ & $\begin{array}{l}\text { Cable driven } \\
\text { method. }\end{array}$ & $\begin{array}{l}\text { Its } 7 \text { degree-of } \\
\text { freedom robotic } \\
\text { arm, which is } \\
\text { excellent for the } \\
\text { robot to be only } \\
\text { more flexible. }\end{array}$ & $\begin{array}{l}\text { Cable driven methods act as a } \\
\text { disadvantage as it is not } \\
\text { feasible, because of the } \\
\text { movement of the robotic arm. }\end{array}$ & [16] \\
\hline $\begin{array}{l}\text { Multiple-Degree-of } \\
\text { Freedom } \\
\text { Counterbalance } \\
\text { Robot Arm Based } \\
\text { on Slider-Crank } \\
\text { Mechanism and } \\
\text { Bevel Gear Units }\end{array}$ & $\begin{array}{l}\text { High probability of } \\
\text { locking. Requires } \\
\text { high precision } \\
\text { control for rotation } \\
\text { of pre- specified } \\
\text { angles. }\end{array}$ & $\begin{array}{l}\text { Slider crank } \\
\text { mechanism }\end{array}$ & $\begin{array}{l}\text { Slider crank } \\
\text { mechanism } \\
\text { decreases the } \\
\text { gravitational } \\
\text { torque. }\end{array}$ & $\begin{array}{c}\text { It is not feasible, as the slider } \\
\text { causes vibrations during the } \\
\text { movement }\end{array}$ & [17] \\
\hline $\begin{array}{l}\text { Design Analysis of } \\
\text { a Remote } \\
\text { Controlled "Pick } \\
\text { and Place" Robotic } \\
\text { Vehicle }\end{array}$ & $\begin{array}{l}\text { High standard of } \\
\text { maintenance } \\
\text { required }\end{array}$ & Pick and Place. & $\begin{array}{l}\text { This design is } \\
\text { useful in dangerous } \\
\text { places or work } \\
\text { areas, its more } \\
\text { accurate and faster } \\
\text { for complicated and } \\
\text { complex duties }\end{array}$ & $\begin{array}{l}\text { Precise programming needed } \\
\text { (time, training, specialist } \\
\text { knowledge). }\end{array}$ & [18] \\
\hline
\end{tabular}

Generally, any autonomous system must contain three main ingredients, mechanical, electrical, and software. The connection among those three ingredients has an effect on the reliability, quality, scalability, and cost of the autonomous system. Therefore, it is important that the three components of automation systems are designed to coexist through an integrated design paradigm [19]-[22]. This sums up the model, design, and construction of an Arduino based robotic arm controlled by a mobile application.

\section{RESEARCH METHOD}

The following describes the design and implementation of a robotic arm controlled with Arduino via Bluetooth, including the characteristics of the robotic arm, extension of the arm, orientation, and the speed. Understanding the geometry of the robotic arm is essential to calculate the angles for its positioning [23]. It is important to know the lengths of each link and the start and end points of the arm in the area of work which is then referenced with respect to the base of the robotic arm or to another point. This motion is described though kinematics whose two types are forward and backward. If the origin point of the robot in the three-dimensional space is $(0,0)$ and the origin cannot be reached, it is described as singularity. The extension of the robotic arm must reach the objects beyond its base to operate its positioning and to control its wrist position. The orientation must be precise in terms of its speed in order to carry objects by the tools provided [24].

The general design of robotic arm in this paper is shown in the Figure 1. This figure illustrates the joints and motors with all their mechanical parts and their movements according to the commands given by the Arduino platform. This design consists of 6 servo motors, which means it has 6 degree of freedom (DOFs), and each motor is controlled independently by the Arduino.

Designing the mechanical parts of the robotic arm is an important and essential process. In order to shape the robotic arm, mechanical parts must be based on how the motors carry their own weight along with the weights of the objects involved. The design of the mechanical parts of the robotic arm requires a software and a $3 \mathrm{D}$ printer that shapes the mechanical parts as necessary.

Solid works 3D printer modeling software, an open source, has been used to produce the parts of the robotic arm. The 3D printer specification that has been used to formulate the parts of robotic arm includes the following: Single nozzle, nozzle diameter $0.4 \mathrm{~mm}$, layering pitch 0.05 to $0.40 \mathrm{~mm}$, modeling speed 10 to $200 \mathrm{~mm} / \mathrm{s}$, and automatic filament supply to nozzle. Also, the interface with 3D printer used USB 2.0, Ethernet, Wi-Fi, or USB memory. 
The complete design of the robotic arm has been shown in Figure 2. This prototype robotic arm has 6 degrees of freedom. For the first 3 joints, the waist, the shoulder, and the elbow, the MG945 servo motors have been used; Figure 3 and Table 2 clarify the characteristics of MG945 servo motors. While for the other 3 joints, the wrist roll and wrist pitch, as well as the gripper, the smaller MG90S micro servo motors have been used. Figure 4 and Table 3 clarify the characteristics of MG90S micro servo motors.

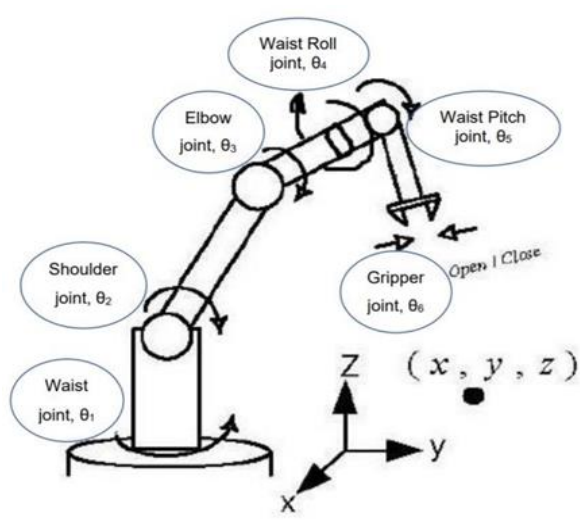

Figure 1. Design of robotic arm

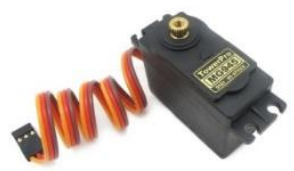

Figure 3. MG945 servo motor [25]

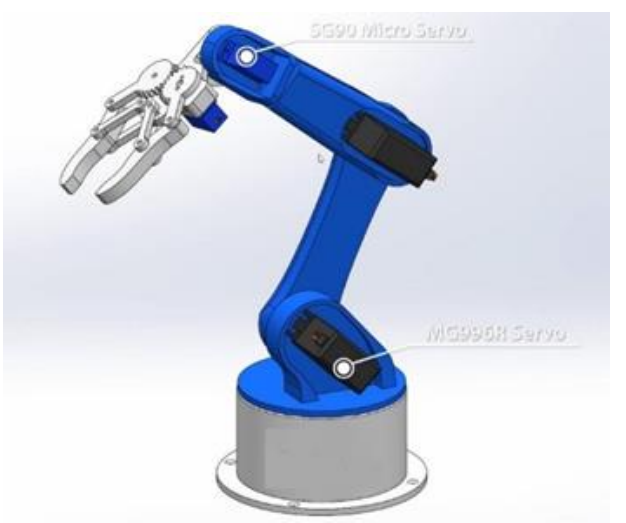

Figure 2. Complete design of the robotic arm in SolidWorks IDE

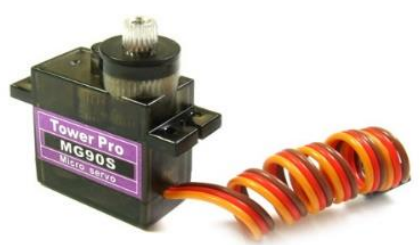

Figure 4. MG90S micro servo motor [25]

Table 2. Specification of MG945 Servo Motor

\begin{tabular}{cc}
\hline Parameter & Value \\
\hline Weight & $100 \mathrm{~g}$ \\
Stall Torque & $10 \mathrm{~kg} / \mathrm{cm}(4.8 \mathrm{~V}): 12 \mathrm{~kg} / \mathrm{cm}(6 \mathrm{~V})$ \\
Operating Speed & $0.23 \mathrm{sec} / 60$ degree $(4.8 \mathrm{~V}): 0.2 \mathrm{sec} / 60$ degree $(6.0 \mathrm{~V})$ \\
Operating Voltage & $4.8 \mathrm{~V}$ a $7.2 \mathrm{~V}$ \\
Dead Band Width & 5 micro s \\
Dimension & $40.7 \times 19.7 \times 42.9 \mathrm{~mm}$ \\
Temperature Range & $0-55$ Degree \\
\hline
\end{tabular}

Table 3. Specification of MG90S Micro Servo Motor

\begin{tabular}{cc}
\hline Parameter & Value \\
\hline Weight & $13.4 \mathrm{~g}$ \\
Dimension & $22.8 \times 12.2 \times 28.5 \mathrm{~mm}$ \\
Operating Speed & $0.1 \mathrm{sec} / 60$ degree $(4.8 \mathrm{v}), 0.08 \mathrm{sec} / 60$ degree $(6 \mathrm{v})$ \\
Operating Voltage & $4.8-6.0$ Volts \\
Dead Band Width & $7 \mathrm{usec}$ \\
Stall Torque & $1.8 \mathrm{~kg} / \mathrm{cm}(4.8 \mathrm{~V}), 2.2 \mathrm{~kg} / \mathrm{cm}(6 \mathrm{~V})$ \\
Temperature Range & -30 to+60 Degree C \\
\hline
\end{tabular}

Figure 5 shows the pin diagram of Arduino Uno Microcontroller platform. It has 6 analog input and 14 digital output/input pins, one $5 \mathrm{~V}$ input, a $3.3 \mathrm{~V}$ input also it consist of a reset button and two inputs: one receives power and the other receives the command from the Arduino IDE. HC-05 module is a simple to use 
Bluetooth SPP serial port protocol (SPP) module, designed for clear wireless serial association setup. The interface Bluetooth module is a completely qualified Bluetooth V2.0+enhanced info rate (EDR) 3 Mbps Modulation with complete a pair of. $4 \mathrm{GHz}$ radio transceiver and baseband [26]. With complementary metaloxide-semiconductor (CMOS) tech, CSR BlueCore 04-External single-chip Bluetooth system with adaptive frequency hopping feature (AFH) can be used, as shown in the Figure 6.

Figure 7 illustrates the flow graph of the designed robotic arm. This figure explains the complete process of the designed Arduino controlled robotic arm. When the operation starts, the robotic arm is in its initial condition. If a command order from the mobile application user is not valid, then the arm will stay at its initial condition. However, if the command order is a valid order, it will be sent to the specific motor and the motor will move accordingly. After the order is complete, the robotic arm returns to its initial condition until a new order is received allowing the process to repeat in a continuous loop until the power is turned off.

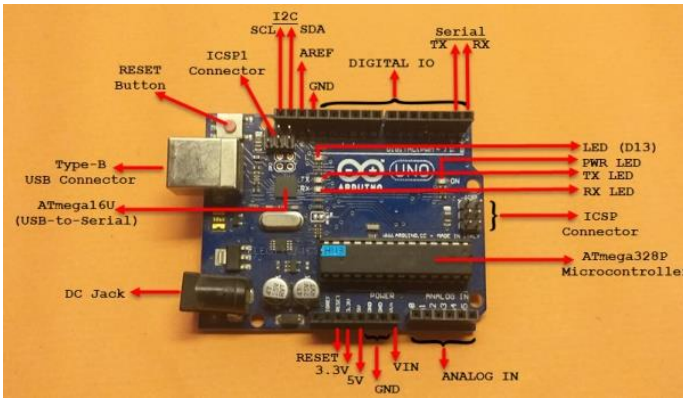

Figure 5. Pin diagram of Arduino Uno microcontroller platform
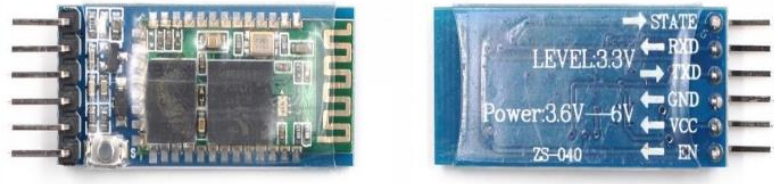

Figure 6. HC-05 serial Bluetooth module [26]

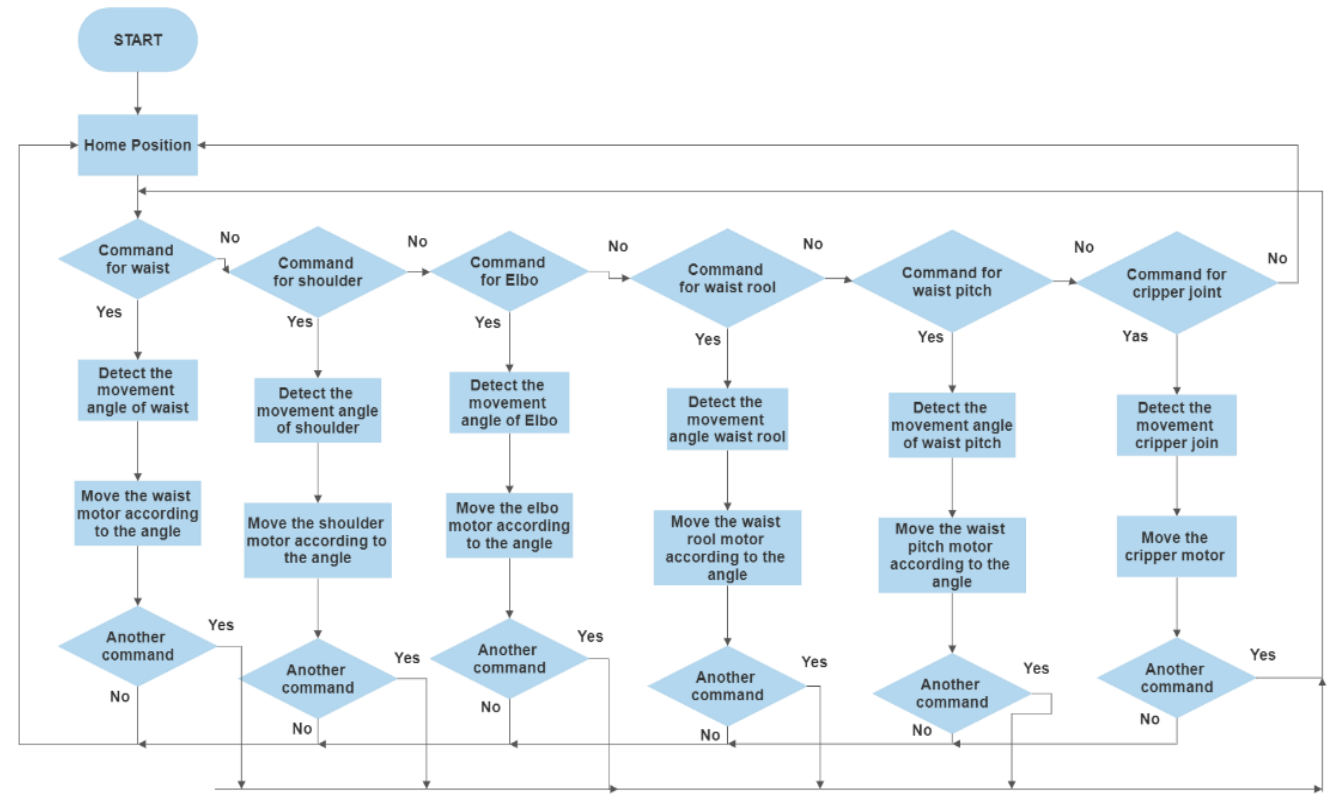

Figure 7. Flow chart of the designed robotic arm

Waist motor movement is to rotate the whole robotic arm on its base from 0 and 180 degree of angle $\theta_{1}$ according to the servo motors rotation range. Shoulder motor movement requires the most strength in the robotic arm as it carries the entire arm's weight. It moves up and down depending on angle $\theta_{2}$. Elbow motor movement is the movement type for more comfortable maneuvering for the robotic arm. Waist roll motor movement is for the rotation of the arm in its axis between 0 and 180 degrees of angle $\theta_{4}$. Waist pitch motor is the up and down maneuver of that joint. Gripper motor movement is the end effector of the arm that reacts with the environment; it only has the ability to grasp objects making its movement only opening and closing. 
The designed robotic arm will be fully controlled by the Arduino platform, therefore, understanding the programming side for the Arduino micro-controller and how its workflows is important. The mechanical parts are the assembling body parts of the robotic arm and the electronic parts are the configuration of the motors, managing the connections of motor wires, Bluetooth module, and creating the mobile application. The robotic arm consists of six servo motors, 3 of them are MG945 servo motors and the other 3 servos are MG90S Micro servos, which are attached to the body parts of the robotic arm, also Arduino Uno, and HC05 Bluetooth module.

In order to form a communication between the user and the robotic arm, there must be a type of medium to transfer the user's commands to the robotic arm. In this research a Bluetooth module has been used to make this communication between mobile user and the robotic arm possible. The user sends the orders by the mobile application to the Arduino via Bluetooth and the Arduino generates the corresponding movements using the robotic arm's motors. In order to make the configuration possible it must be programmed so that the Arduino can enable the mobile device's Bluetooth. The programming of the robot needs to be accurate to control each servo motor with its related motion. The designed application has sliders and each slider is related with one motor movement; when the user changes the sliders in the application, the motors will move accordingly.

Arduino IDE has been used for Arduino programming, which is an open-source software owned by Arduino Company. For the mobile application used in this system, it enables the phone's Bluetooth in order to connect with the robotic arm, as shown in the Figure 8. All the servo motors are connected to the $5 \mathrm{~V}$ external power supply directly which must be at least $1000 \mathrm{~mA} \mathrm{dc}$ maximum current depending on the standards of motors that are used in the system, the $2000 \mathrm{~mA}$ is recommended. The Bluetooth module is not powered directly by the $5 \mathrm{~V}$ adapter, for safety reasons, it's powered through the Arduino board which is connected to the power supply directly. The GND of all the servo motors and the Arduino's GND are connected to each other.

The MIT App Inventor is used for creating the application. The mobile application that is created in this project contains a button for enabling the Bluetooth of the mobile device and 6 sliders for each servo motor to give commands and move them accordingly. For the Mobile application, the user must go to the blocks section in order to code the application. The same idea is applied as the code of Arduino, for 6 servo motors there are 6 sliders in the application to give the angles, thus it has to send a value via Bluetooth to the Arduino in order to move the servo motors.

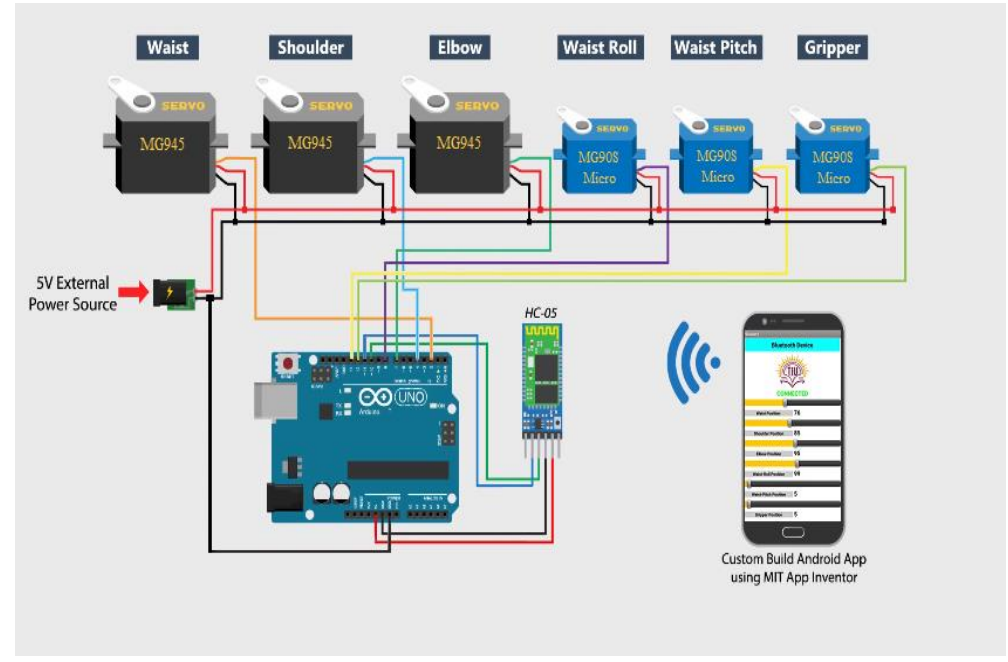

Figure 8. Circuit diagram of robotic arm

\section{RESULTS AND TESTING THE SYSTEM}

The results of testing the designed robotic arm system are explained as follows. The test of the designed robotic arm has been conducted depending on the speed, force, and balance of the movement, therefore showing that the robotic arm is capable of handling its weight, force, and balance properly. Testing the mobile application proved that it is working well without any errors. First, when the robotic arm is powered ON, all motors of the robotic arm go directly to the home position depending on receiving signal from the mobile application as shown in Figure 9. The application communicates with the robotic arm by the Bluetooth 
module as the commands are sent to the robotic arm via Bluetooth and the robotic arm responds to the commands properly, as shown in the Figure 10. The movement's tests have been explained in Table 4.

In the Figure 10, the test results are presented: (a) waist, (b) shoulder, (c) elbow motors, (d) waist-roll, (e) waist-pitch, and (f) gripper motors. According to the test results of the project, the Arduino controlled robotic arm is capable of doing great work compared to its size and speed of movement. It is easy to use, simple to handle, and can be easily screwed to a stationary place where the work is needed or unscrewed to be moved somewhere else. Ultimately, this is only the beginning of a new era of technology for robots whether it be in our daily lives or in companies as robots can save tremendous amount of time, reduce cost, and contribute to many other benefits.

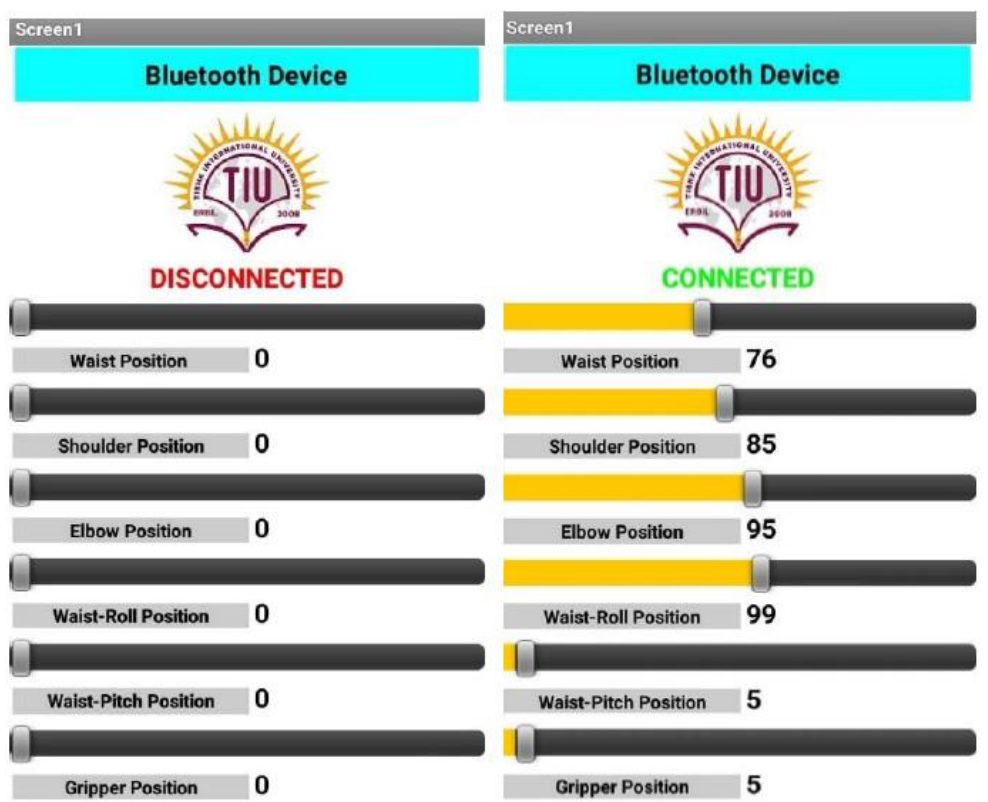

Figure 9. Before and after connecting mobile application to Arduino (home position)

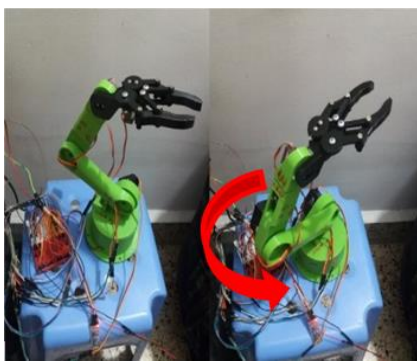

(a)

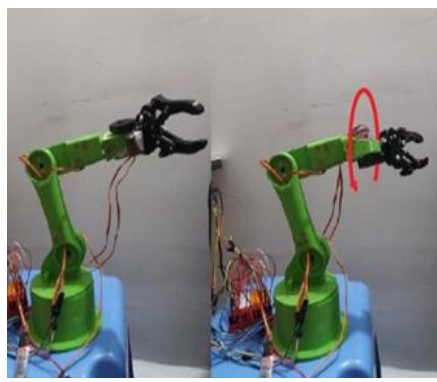

(d)

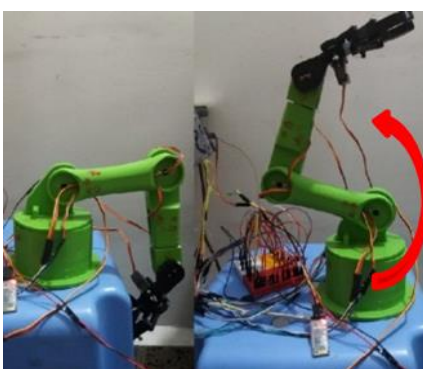

(b)

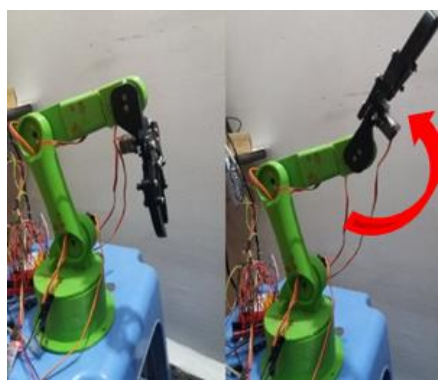

(e)

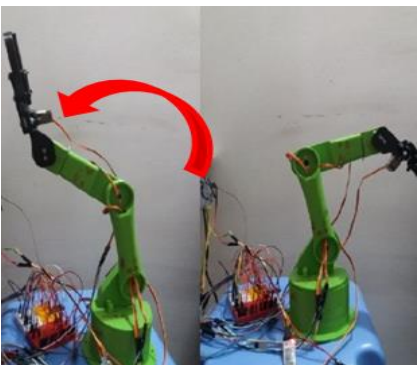

(c)

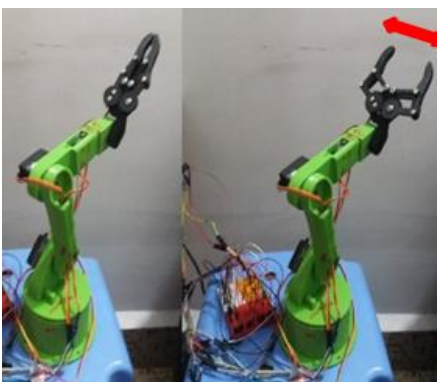

(f)

Figure 10. Testing the robotic arm I, (a) waist, (b) shoulder, (c) elbow motors, (d) waist-roll, (e) waist-pitch, and (f) gripper motors) 
Table 4. Testing of the designed robotic arm

\begin{tabular}{cc}
\hline Command & Action \\
\hline $\begin{array}{c}\text { Waist motor movement is rotating according to the value sent by the mobile application which is } \\
\text { in this direction is from 5 degrees to 146 degrees. (Angle range 5-175 degree) }\end{array}$ & Figure 10(a) \\
$\begin{array}{c}\text { Shoulder joint motor movement is rotating according to the value sent by the mobile application } \\
\text { which is in this direction is from 7 degrees to 166 degrees. (Angle range 5-175 degree) }\end{array}$ & Figure 10(b) \\
$\begin{array}{c}\text { Elbow joint motor movement is rotating according to the value sent by the mobile application } \\
\text { which is in this direction is from 5 degrees to 173 degrees. (Angle range 5-175 degree) }\end{array}$ & Figure 10(c) \\
$\begin{array}{c}\text { Waist-roll joint motor movement is rotating according to the value sent by the mobile application } \\
\text { which is in this direction is from 7 degrees to 175 degrees. (Angle range 5-175 degree) }\end{array}$ & Figure 11(a) \\
$\begin{array}{c}\text { Waist-pitch joint motor movement is rotating according to the value sent by mobile application } \\
\text { which is in this direction is from 20 degrees to 167 degrees. (Angle range 5-175 degre) }\end{array}$ & Figure 11(b) \\
$\begin{array}{c}\text { Gripper joint motor movement is rotating according to the value sent by the mobile application } \\
\text { which is in this direction is from 11 degrees to 173 degrees. (Angle range 5-165 degree) }\end{array}$ & Figure 11(c) \\
\hline
\end{tabular}

\section{CONCLUSION}

This research is intended to design a robotic arm fully controlled by Arduino platform over a safe distance through a mobile application. This robotic arm can be used in plenty of different industries or in areas which are unsafe for humans. The Arduino has been programmed to provide rotation to each servo motor corresponding to the sliders in the designed mobile application for usage from a distance. The final design has been tested and the results show that this design completes its job accordingly.

\section{REFERENCES}

[1] C. S. Chen, S. K. Chen, C. C. Lai, and C. T. Lin, "Sequential motion primitives recognition of robotic arm task via human demonstration using hierarchical BiLSTM classifier," IEEE Robotics and Automation Letters, vol. 6, no. 2, pp. 502-509, Apr. 2021, doi: 10.1109/LRA.2020.3047772.

[2] X. Chen, X. Huang, Y. Wang, and X. Gao, "Combination of augmented reality based brain- computer interface and computer vision for high-level control of a robotic arm," IEEE Transactions on Neural Systems and Rehabilitation Engineering, vol. 28, no. 12, pp. 3140-3147, Dec. 2020, doi: 10.1109/TNSRE.2020.3038209.

[3] P. Sutyasadi and M. B. Wicaksono, "Joint control of a robotic arm using particle swarm optimization based H2/Hळ robust control on arduino," TELKOMNIKA (Telecommunication Computing Electronics and Control), vol. 18, no. 2, Apr. 2020, Art. no. 1021, doi: 10.12928/telkomnika.v18i2.14749.

[4] A. H. Basori, "End-effector wheeled robotic arm gaming prototype for upper limb coordination control in home-based therapy," TELKOMNIKA (Telecommunication Computing Electronics and Control), vol. 18, no. 4, Aug. 2020, Art. no. 2080, doi: 10.12928/telkomnika.v18i4.3775.

[5] T. T. Nguyen, "Sliding mode control-based system for the two-link robot arm," International Journal of Electrical and Computer Engineering, vol. 9, no. 4, pp. 2771-2778, Aug. 2019, doi: 10.11591/ijece.v9i4.pp2771-2778.

[6] T. T. Nguyen, "Fractional-order sliding mode controller for the two-link robot arm," International Journal of Electrical and Computer Engineering, vol. 10, no. 6, pp. 5579-5585, Dec. 2020, doi: 10.11591/ijece.v10i6.pp5579-5585.

[7] A. Singh, P. Pandey, and G. C. Nandi, "Effectiveness of multi-gated sequence model for the learning of kinematics and dynamics of an industrial robot," Industrial Robot, vol. 48, no. 1, pp. 62-70, Dec. 2021, doi: 10.1108/IR-01-2020-0010.

[8] M. Bugday and M. Karali, "Design optimization of industrial robot arm to minimize redundant weight," Engineering Science and Technology, an International Journal, vol. 22, no. 1, pp. 346-352, Feb. 2019, doi: 10.1016/j.jestch.2018.11.009.

[9] M. Anisur Rahman, A. Khan, T. Ahmed, and M. Sajjad, "Design, analysis and implementation of a robotic arm-the animator," International Journal of Engineering Research, vol. 2, no. 10, pp. 298-307, 2013.

[10] R. Jain, M. Nayab Zafar, and J. C. Mohanta, "Modeling and analysis of articulated robotic arm for material handling applications," IOP Conference Series: Materials Science and Engineering, vol. 691, no. 1, Dec. 2019, Art. no. 12010, doi: 10.1088/1757899X/691/1/012010.

[11] M. A. Alblaihess, "Designing a robotic arm for moving and sorting scraps at Pacific Can, Beijing, China," Beijing, 2015.

[12] Y. Hashim and M. N. Shakib, "Automatic control system of highway lights," TELKOMNIKA (Telecommunication Computing Electronics and Control), vol. 18, no. 6, Dec. 2020, Art. no. 3123, doi: 10.12928/telkomnika.v18i6.16497.

[13] K. Zhang, C. Hutson, J. Knighton, G. Herrmann, and T. Scott, "Radiation tolerance testing methodology of robotic manipulator prior to nuclear waste handling," Frontiers in Robotics and AI, vol. 7, Feb. 2020, doi: 10.3389/frobt.2020.00006.

[14] R. Smith, E. Cucco, and C. Fairbairn, "Robotic development for the nuclear environment: challenges and strategy," Robotics, vol. 9 , no. 4, pp. 1-16, Nov. 2020, doi: 10.3390/robotics9040094.

[15] M. Kafuko, I. Singh, and T. Wanyama, "Design of a robotic arm for teaching integrated design," Proceedings of the Canadian Engineering Education Association (CEEA), Aug. 2015, doi: 10.24908/pceea.v0i0.5827.

[16] S. K. Mustafa, G. Yang, S. H. Yeo, W. Lin, and I. M. Chen, "Self-calibration of a biologically inspired 7 DOF cable-driven robotic arm," IEEE/ASME Transactions on Mechatronics, vol. 13, no. 1, pp. 66-75, Feb. 2008, doi: 10.1109/TMECH.2007.915024.

[17] H. S. Kim, J. K. Min, and J. B. Song, "Multiple-degree-of-freedom counterbalance robot arm based on slider-crank mechanism and bevel gear units," IEEE Transactions on Robotics, vol. 32, no. 1, pp. 230-235, Feb. 2016, doi: 10.1109/TRO.2015.2501746.

[18] B. O. Omijeh and R. Uhunmwangho, "Design analysis of a remote controlled 'pick and place' robotic vehicle," International Journal of Engineering Research and Development, vol. 10, no. 5, pp. 57-68, 2014.

[19] R. F. Abdel-Kader, M. Nashaat, M. I. Habib, and H. M. K. Mahdi, "Automated server-side model for recognition of security vulnerabilities in scripting languages," International Journal of Electrical and Computer Engineering (IJECE), vol. 10, no. 6, Dec. 2020, Art. no. 6061, doi: 10.11591/ijece.v10i6.pp6061-6070.

[20] Y. Hashim, "Design of arduino-based dual axis solar tracking system," Journal on Advanced Research in Electrical Engineering, vol. 4, no. 2, pp. 129-133, 2020.

[21] Y. Hashim, A. H. B. M. Idzha, and W. A. Jabbar, "The design and implementation of a wireless flood monitoring system," Journal 
of Telecommunications and Information Technology, vol. 10, no. 3-2, pp. 7-11, 2018.

[22] W. K. Saad, Y. Hashim, and W. A. Jabbar, "Design and implementation of portable smart wireless pedestrian crossing control system," IEEE Access, vol. 8, pp. 106109-106120, 2020, doi: 10.1109/ACCESS.2020.3000014

[23] K. Kruthika, B. M. Kiran Kumar, and S. Lakshminarayanan, "Design and development of a robotic arm," Oct. 2017, doi: 10.1109/CIMCA.2016.8053274.

[24] A. Chavan, A. Bhuskute, A. Jain, N. Shinde, and M. Salunke, "Implementation of generic multi-purpose robotic arm," International Journal of Computer Applications, vol. 116, no. 18, pp. 22-27, Apr. 2015, doi: 10.5120/20437-2775.

[25] A. Basu, S. A. Moosavian, and R. Morandini, "Mechanical optimization of servo motor," Journal of Mechanical Design, Transactions of the ASME, vol. 127, no. 1, pp. 58-61, Jan. 2005, doi: 10.1115/1.1804196.

[26] A. Cotta and N. T. Devidas, "Wireless communication using hc-05 bluetooth module interfaced with Arduino," International Journal of Science, Engineering and Technology Research (IJSETR), vol. 5, no. 4, 2016

\section{BIOGRAPHIES OF AUTHORS}
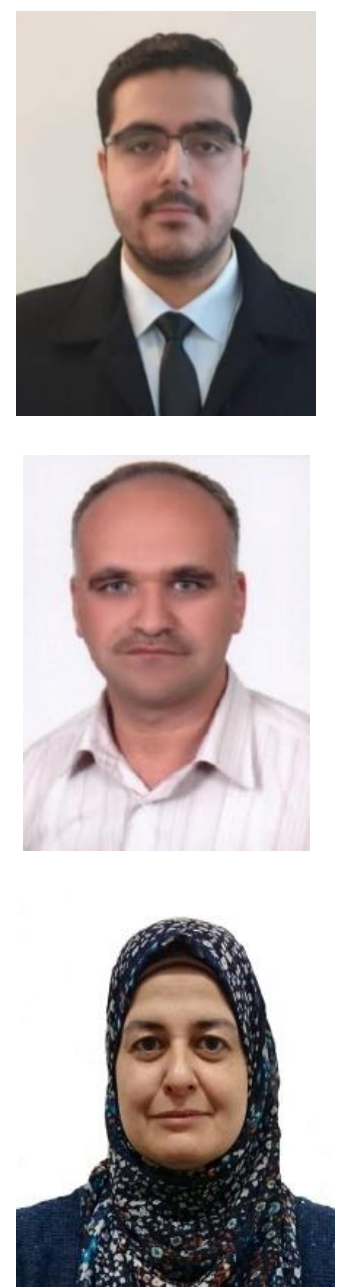

Hussein Mohammed Ali (D) SC P received the B.Sc. in Computer Engineering from Tishk International University, Erbil, Iraq, in 2020. He is currently Research Assistant in the Department of Computer Engineering, Faculty of Engineering, Tishk International University, Erbil-Kurdistan, Iraq. He can be contacted at email: hussein.mohammed@tiu.edu.iq.

Yasir Hashim (iD SC SC (SMIEEE) received the B.Sc. and master of Engineering in Electronics and Communications Engineering from the University of Mosul, Mosul, Iraq, in 1991 and 1995 respectively. He completed the Ph.D. in Electronics Engineering-Micro and Nanoelectronics from Universiti Science Malaysia (USM), Penang, Malaysia, in 2013. His research interests include Microelectronics and Nanoelectronic: Nanowire transistors, FinFET transistor, Multistage Logic Nano-inverters. He is currently a Senior Lecturer in the Department of Computer Engineering, Faculty of Engineering, Tishk International University, ErbilKurdistan, Iraq. He can be contacted at email: yasir.hashim@tiu.edu.iq, yasir.hashim@ieee.org.

Ghadah Alaadden. Al-Sakkal (D) SI SC P received the B.Sc. and master of Mathematics in Mathematical Science from Al-Mustansiriyya University of Baghdad, Iraq in 1987 and 1999 respectively. She is currently a Lecturer in the Department of Computer Engineering, Faculty of Engineering, Tishk International University, Erbil-Kurdistan, Iraq. She can be contacted at email: ghada.alsakkal@tiu.edu.iq. 